Article

\title{
Factors Influencing Indirect Carbon Emission of Residential Consumption in China: A Case of Liaoning Province
}

\author{
Yan Yan ${ }^{1}$, Ancheng Pan ${ }^{1}{ }^{1 *}$, Chunyou $\mathrm{Wu}^{1}$ and Shusen Gui ${ }^{2}$ \\ 1 Faculty of Management and Economics, Dalian University of Technology, Dalian 116024, China \\ 2 China Business Executives Academy at Dalian, Dalian 116086, China \\ * Correspondence: ancheng@aliyun.com
}

Received: 12 July 2019; Accepted: 4 August 2019; Published: 15 August 2019

check for updates

\begin{abstract}
Indirect carbon emissions caused by residential consumption has gradually become the key to the formulation of carbon emission reduction policies. In order to analyze the factors that influence the provincial residential indirect carbon emissions in China, comprehensive structural decomposition analysis (SDA) and logarithmic mean Divisia index (LMDI) models are established in this paper. The Liaoning province was selected due to its typical features as a province with higher urbanization rates. The model is based on input-output tables from 2002 to 2012, including those pertaining to the carbon emission coefficient $(\Delta \mathrm{F})$, energy intensity effect $(\Delta \mathrm{E})$, intermediate demand $(\Delta \mathrm{L})$, commodity structure $(\Delta \mathrm{S})$, residential consumption structure $(\Delta \mathrm{U})$, residential consumption ratio $(\Delta \mathrm{R})$, per capita GDP $(\Delta \mathrm{A})$ and population size $(\Delta \mathrm{P})$. The results show that the consumption of urban residents is the most common and significant section causing the growth of direct and indirect carbon emissions, both of which show an obvious upward trend. Nonmetal mining is the sector experiencing the greatest growth in indirect carbon emissions. The two most influential factors of indirect carbon emissions via the consumption of rural and urban residents are the intermediate demand effect $(\Delta \mathrm{L})$ and the per capita GDP effect $(\Delta \mathrm{A})$, respectively. Reducing energy intensity and optimizing commodity structures are the most effective ways to reduce indirect carbon emissions.
\end{abstract}

Keywords: residential consumption; indirect carbon emission; SDA decomposition; LMDI decomposition

\section{Introduction}

The phenomenon of global climate change caused by the rapid increase of greenhouse gases has changed from being a simple scientific problem to a complex political, economic, social and development issue. For the past few years, the Chinese economy has been developing rapidly and steadily. People's living standards have also significantly improved, but this improvement occurred following a rise in carbon emissions. According to BP's statistical results, China became the world's largest carbon emitter in 2008 [1,2]. The country's energy consumption and carbon emissions accounted for $22.4 \%$ and $27.1 \%$ of the world's total, respectively, in 2013. Expanding domestic and residential consumption is one of the main paths to maintaining steady economic growth. However, carbon emissions caused by direct and indirect residential consumption have become the second largest carbon emission sector (after industry) in China's terminal consumption sector [3]. Besides, Fonseca et al. [4] and Shaharudin et al. [5] researched domestic consumption from the perspective of Circular Economy (CE) and low carbon supply chain (LCSC), respectively. They pointed out that future research needs to integrate domestic consumption into carbon emission reduction policy analysis models, to understand how policy makers can encourage industry to comply with low carbon emissions. The problem of the carbon emissions generated by Chinese residents' lifestyles cannot be ignored. As the world's largest 
developing country and a major party to global climate talks, China is shouldering great pressure to reduce emissions, while also shouldering great responsibility for reducing them.

Therefore, more and more researchers have focused their attention on the energy-related carbon emissions caused by residential consumption [6-11]. Direct carbon emissions from residential consumption, calculated from China's Statistical Yearbook, are not large, so they can easily be ignored. Indirect emissions caused by residential consumption include carbon emissions generated during the production of consumer products. This can provide a more comprehensive explanation of the impacts of household consumption on China's overall carbon emissions and can also help identify key sectors for carbon reduction. Wang and Yang [12] empirically analyzed the influencing factors of resident $\mathrm{CO}_{2}$ emissions by the Consumer Lifestyle Approach (CLA) and Net Primary Productivity (NPP) using an improved Stochastic Impacts by Regression on Population, Affluence, and Technology (STIRPAT) model. The result showed that urban residents' consuming pattern had an important effect on reducing $\mathrm{CO}_{2}$ emissions.

One of the important methods to estimate the amount of carbon emissions caused by residents' consumption is input-output analysis (IOA), first introduced by American economist W. Leontief [13]. The IOA method is primarily aimed at solving the dependency between input and output in an economic system. By the 1960s, IOA had already been widely used in the fields of economic development, environmental impact and energy [14-18]. Li et al. [19] assessed the living carbon emissions of Chinese residents from 1996 to 2012, using the IOA method. The study explores the relationship between urbanization levels and carbon emission growth. Ma et al. [20] used the IOA method to compare indirect carbon emissions caused by Chinese and American household consumption.

From the perspective of carbon emission factor decomposition, in recent years, the structural decomposition analysis (SDA) method has gradually become an important tool for empirical studies of domestic and foreign input-output technologies [13,21,22]. Tian et al. [23] used the SDA model to analyze the relationship between carbon dioxide emissions and energy intensity in Beijing, China. Gui et al. [24] extracted and analyzed the factors and strategic supply chains involved in changes in carbon dioxide emission levels from 1992 to 2007. Wang and Wang [25] examined the driving forces for the increment in energy-related $\mathrm{CO}_{2}$ emissions in Xinjiang, from 1997 to 2007. The study used an environmental input-output (IO)-SDA to reach its conclusions. Based on their results, Xinjiang would find curbing $\mathrm{CO}_{2}$ emissions in the future to be a great challenge. $\mathrm{Xu}$ et al. [26] decomposed the factors affecting Jiangsu's $\mathrm{CO}_{2}$ emissions using the SDA method. The results showed that energy intensity had a great reducing effect, but energy structure had only a minimal effect. Xu et al. [27] decomposed the factors affecting China's energy-related air pollutant emissions during the period 2005 to 2012, using an IO-SDA method. They found that exports and imports slightly increased the emissions on the whole, while input-output efficiency slightly reduced emissions. Yan et al. [28] studied China's $\mathrm{CO}_{2}$ intensity changes from 2002 to 2012, using a multiplicative structural decomposition and attribution analysis. The conclusions showed that the energy intensity effect was the major driver in reducing China's emission intensity.

However, during the SDA decomposition process, interactive item problems will inevitably occur, such as inconsistent measurement results, weak comparability of factor weights, and difficulties associated with interactive impact decomposition. Dietzenbacher and Los [29,30] conducted an empirical study on the uniqueness of the decomposition method and the independence of variables. The study points out that, if the number of decomposed factors is $n$, the number of possible decomposition forms is $n$ !. While the two-pole decomposition method, the midpoint weight decomposition method, the weighted average decomposition method and other methods are used to solve the above problems, these methods use different techniques to merge the interaction terms into other terms. This results in large differences in the decomposition results, which in turn reduces the accuracy of the decomposition results and the reliability of the conclusions. The logarithmic mean Divisia index (LMDI) model can overcome cross term problems very well [31,32]. The LMDI model can decompose multiple factors, and the decomposition result does not contain the unexplainable residual 
terms. This model has been widely used at home and abroad in the study of energy consumption [33-35] and carbon emissions-related factors [36,37]. However, this method also has the disadvantage of a limited decomposition path. The carbon emission effects of trade, demand and other factors cannot be analyzed. Therefore, if these two methods are combined, they are not only able to overcome their shortcomings, but they also give full play to their advantages. Thus, they will have higher accuracy and greater applicability in decomposition [38]. Wang et al. [39] identified the driving forces that influence the changes in carbon emissions caused by China's residential consumption, using the SDA and LMDI methods. The results showed that the consumption level and emission intensity were the main drivers that influence the change in indirect carbon emissions. Wang and Yang [8] analyzed the influencing factors affecting urban and rural residential carbon emissions in Beijing, through both IO-SDA and LMDI. The study's results showed that per capita GDP presented the biggest growth effect on residential consumption, and indirect carbon emissions and energy intensity were the most important factors in reducing indirect carbon emissions.

Liaoning province has been playing an important role in China's economic development since the establishment of China. As one of the earliest Chinese heavy-industry bases, Liaoning provides favorable support for China's industrial development and infrastructure construction in all aspects. Since the beginning of the 21st century, Liaoning's position in China has become increasingly important, and plays an important role in the healthy and stable development of China's economy. In the process of deepening China's economic reform and opening up in the new era, people are paying more and more attention to what needs to be done to realize the healthy and sustainable development of Liaoning's economy. O'Neill et al. [40] pointed out that urbanization would be an important factor influencing global greenhouse gas emissions for the next 40 years. For some developing countries, urban population growth would account for as much as $25 \%$ of carbon dioxide emissions growth. Liaoning province is one of the provinces with the largest carbon emissions and the highest urbanization rate. The research of Geng et al. [41] indicated a rapid growth trend of $\mathrm{CO}_{2}$ emission in Liaoning province during 1997-2007. Huge emissions and a high urbanization rate have a serious impact on the environment. Urbanization affects energy consumption and carbon emissions by changing both production processes and lifestyle. Among these production processes, energy conservation and emission reduction require technological progress and industrial structure transformation, which must be reflected over a long period of time. These things are difficult to improve in a short period of time through human factors and intervention. However, achieving energy conservation and emission reduction in the consumption processes of residents can be realized through the residents' conscious awareness of emission-reducing and energy-saving consumption habits. In the urbanization process, with a reduction or even a significant reduction of per capita living energy consumption, as long as the living standard of residents is not negatively impacted, the great pressure on Liaoning province to reduce emissions will be eased. Therefore, it is very important to make an in-depth analysis of the indirect carbon emissions generated by residential consumption in the urbanization process of Liaoning.

In this paper, the indirect carbon emissions caused by urban and rural residential consumption in Liaoning province are estimated. In the following section, we describe the method of estimating direct and indirect carbon emissions by residential consumption. The LMDI model is also introduced, in order to analyze the influencing factors affecting residential carbon emissions indicators. In Section 3, we discuss the data used in this paper. Empirical findings that reveal the influence mechanism of Liaoning's carbon emission changes are presented in Section 4. Finally, we provide services to help the formulation of Liaoning's emission reduction policies, as well as our conclusions, in Section 5.

\section{Methodology}

\subsection{Calculation of Direct Carbon Emissions from Residential Consumption}

The IPCC (Intergovernmental Panel on Climate Change) reference method is an important method used to calculate the direct carbon emissions caused by energy consumption. The IPCC method is also 
known as the emission factor method [42]. At present, most countries use the emission factor method as the default method to calculate emissions, based on the 2006 IPCC national greenhouse gas inventory guidelines [43]. International organizations and institutions such as the IEA (International Energy Agency) and IPCC are continually improving greenhouse gas emission inventory and assessment methods. Wang et al. [44] used the IPCC reference method to evaluate the $\mathrm{CO}_{2}$ emissions caused by energy consumption in Guangdong Province, China, and then discussed the influencing factors. Qu et al. [45] evaluated the carbon emissions generated by the direct energy sources of Chinese urban and rural residents, using the IPCC reference method and based on China's statistical data. The results showed that there are significant differences in $\mathrm{CO}_{2}$ emissions between urban and rural energy consumption in China. Xu et al. [46] assessed the carbon emissions of 18 cities in 6 urban areas in central China by using the IPCC reference method. The study analyzed the time evolution characteristics and industrial structure characteristics of each of these locations. The IPCC reference method is applicable to the assessment of greenhouse gas emissions generated by energy consumption, as well as to the assessment of carbon emissions generated by direct energy consumption in the life of residents [42,43].

The direct carbon emissions of residential consumption correspond to the direct energy consumption of residents, and directly relate to the carbon emissions brought about by residents in the process of direct energy consumption. Carbon emissions are generated by the use of residential energy for lighting, cooking, heating and private transportation. These types of energy typically include coal, gasoline, natural gas and electricity.

The carbon emission coefficient method is used to calculate the direct carbon emissions of residential consumption. The estimation model is as follows:

$$
D C_{\alpha}=\sum_{k=1}^{m} V_{k} \cdot W_{\alpha c}
$$

where $D C_{\alpha}$ represents the direct carbon emissions generated by the direct consumption of commodity energy by residents $\alpha, \alpha=$ rural and urban; $V_{k}$ is the carbon emissions coefficient for energy type $k ; m$ is the number of energy types, and $W_{\alpha c}$ is the direct consumption of type $k$ energy by residents $\alpha$.

\subsection{Indirect Carbon Emissions from Residential Consumption}

The indirect carbon emissions of residents correspond to the indirect energy consumption of residents, which directly relate to the carbon emissions from the indirect energy consumption caused by residents' consumption of various goods and services. This is partly due to commodity-embodied energy consumption, which can be divided into indirect carbon emissions caused by urban residents and indirect carbon emissions caused by rural residents. Compared with the direct carbon emissions of residential consumption, this category of carbon emissions is implicit and easy to ignore, but it is very important, because the amount of this type of emissions is often much higher than the direct carbon emissions. With the advancement of urbanization, changes in residents' lifestyles have accelerated the growth of these emissions, which has become the focus of emission reduction efforts.

In the accounting of indirect emissions, a non-competitive input-output table is used to exclude the carbon emissions caused by the consumption of imported goods by residents, as well as the use of imported raw materials by the production department. In theory, the results are more scientific. The input-output model for calculating indirect carbon emissions from residential consumption is shown below:

$$
I C_{\alpha}=F E(I-A)^{-1} Y_{\alpha}
$$

From the sector view, it can be shown as:

$$
I C_{\alpha i}=\sum_{j=1}^{n} F_{i} E_{i}\left(I-A_{i j}\right)^{-1} Y_{\alpha j}
$$


where $I C_{\alpha i}$ is the indirect carbon emissions of sector $i$ caused by the consumption of resident $\alpha ; F_{i}$ is the carbon emission coefficient of sector $i$, equal to the ratio of total carbon emissions to the total energy consumption of the sector $i$; $E_{i}$ is the energy intensity of sector $i$, equal to the energy consumption per unit of gross output of sector $i$; $A_{i j}$ is the direct requirement matrix containing the ratios of the amount of each input directly required to produce one unit of a product; and $I$ is an identity matrix. Then $\left(I-A_{i j}\right)^{-1}$ is the Leontief inverse square matrix, representing the complete demand coefficient matrix, and $Y_{\alpha j}$ is the final consumption of sector $j$ by resident $\alpha$. Assuming that $(I-A)^{-1}=L$, then:

$$
I C_{\alpha}=\sum_{i=1}^{n} I C_{\alpha i}=\sum_{i=1}^{n} \sum_{j=1}^{n} F_{i} E_{i} L_{i j} Y_{\alpha j}
$$

where $I C_{\alpha}$ is the total indirect carbon emissions caused by the consumption of resident $\alpha$.

\subsection{The Decomposition Models}

The basic idea of the structure decomposition analysis (SDA) is to decompose the system's dependent variables into the sum or product of different forms of the related variables. This is done to measure the contribution of each variable to the dependent variable's variation. In this model, the final consumption of rural or urban residents is eventually decomposed as follows:

$$
I C_{\alpha i}=\sum_{j=1}^{n} F_{i} E_{i} L_{i j}\left(\frac{Y_{\alpha j}}{\sum_{j=1}^{n} Y_{\alpha j}}\right)\left(\frac{\sum_{j=1}^{n} Y_{\alpha j}}{\sum_{\alpha=1}^{2} \sum_{j=1}^{n} Y_{\alpha j}}\right)\left(\frac{\sum_{\alpha=1}^{2} \sum_{j=1}^{n} Y_{\alpha j}}{G D P}\right)\left(\frac{G D P}{P}\right) P .
$$

Assuming that

$$
S_{\alpha j}=\frac{Y_{\alpha j}}{\sum_{j=1}^{n} Y_{\alpha j}}, U_{\alpha}=\frac{\sum_{j=1}^{n} Y_{\alpha j}}{\sum_{\alpha=1}^{2} \sum_{j=1}^{n} Y_{\alpha j}}, R=\frac{\sum_{\alpha=1}^{2} \sum_{j=1}^{n} Y_{\alpha j}}{G D P}, A=\frac{G D P}{P}
$$

where $S_{\alpha j}$ represents the proportion of commodity $j$ in the consumption of resident $\alpha ; U_{\alpha}$ represents the proportion of resident $\alpha$ in total residential consumption; $R$ represents the ratio of total residential consumption to GDP in the year; $A$ is the per capita GDP in the year; and $P$ is the population size in the year. Therefore, the model for calculating the indirect carbon emissions, coming from the consumption of resident $\alpha$ to sector $i$, is shown below:

$$
I C_{\alpha i}=\sum_{j=1}^{n} F_{i} E_{i} L_{i j} S_{\alpha j} U_{\alpha} R A P .
$$

Consequently, the indirect carbon emissions' change of sector $i$ caused by the consumption of resident $\alpha$ between base year 0 and target year $t$ can be expressed as:

$$
\Delta I C_{\alpha i}=\sum_{j=1}^{n} F_{i}^{t} E_{i}{ }^{t} L_{i j}{ }^{t} S_{\alpha j}{ }^{t} U_{\alpha}{ }^{t} R^{t} A^{t} P^{t}-\sum_{j=1}^{n} F_{i}^{0} E_{i}{ }^{0} L_{i j}{ }^{0} S_{\alpha j}{ }^{0} U_{\alpha}{ }^{0} R^{0} A^{0} P^{0} .
$$

According to the SDA method, the total variation can be understood as the sum of the variation of different influencing factors. A typical SDA of macro-variables that includes 8 components is established in this paper. The factors include: The carbon emission coefficient effect $(\Delta F)$; the energy intensity effect $(\Delta E)$; the intermediate demand effect $(\Delta L)$; the commodity structure effect $(\Delta S)$; the 
residential consumption structure effect $(\Delta U)$; the residential consumption ratio effect $(\Delta R)$; the per capita GDP effect $(\Delta A)$; and the population size effect $(\Delta P)$. The total effect on indirect carbon emissions can be decomposed into the sum of the contribution of the influencing factors:

$$
\Delta I C_{\alpha}=\Delta F+\Delta E+\Delta L+\Delta S_{\alpha}+\Delta U_{\alpha}+\Delta R+\Delta A+\Delta P .
$$

For reasons of exact decomposition, a non-parametric method and ease of use [13], the LMDI decomposition technique method is introduced in this paper to calculate the effect of each factor. The LMDI method was first applied in SDA by Wachsmann et al. [47]. Assuming that

$$
M_{\alpha i j}=\frac{I C_{\alpha i j}^{t}-I C_{\alpha i j}^{0}}{\ln \left(I C_{\alpha i j}^{t}\right)-\ln \left(I C_{\alpha i j}^{0}\right)} .
$$

The carbon emission coefficient effect:

$$
\Delta F=\sum_{i=1}^{n} \sum_{j=1}^{n} M_{\alpha i j} \ln \left(\frac{F_{i}^{t}}{F_{i}^{0}}\right) .
$$

The energy intensity effect:

$$
\Delta E=\sum_{i=1}^{n} \sum_{j=1}^{n} M_{\alpha i j} \ln \left(\frac{E_{i}^{t}}{E_{i}^{0}}\right) .
$$

The intermediate demand effect:

$$
\Delta L=\sum_{i=1}^{n} \sum_{j=1}^{n} M_{\alpha i j} \ln \left(\frac{L_{i j}^{t}}{L_{i j}^{0}}\right) .
$$

The commodity structure effect:

$$
\Delta S_{\alpha}=\sum_{i=1}^{n} \sum_{j=1}^{n} M_{\alpha i j} \ln \left(\frac{S_{\alpha j}^{t}}{S_{\alpha j}^{0}}\right) .
$$

The residential consumption structure effect:

$$
\Delta U_{\alpha}=\sum_{i=1}^{n} \sum_{j=1}^{n} M_{\alpha i j} \ln \left(\frac{U_{\alpha}^{t}}{U_{\alpha}^{0}}\right) .
$$

The residential consumption ratio effect:

$$
\Delta R_{\alpha}=\sum_{i=1}^{n} \sum_{j=1}^{n} M_{\alpha i j} \ln \left(\frac{R_{\alpha}^{t}}{R_{\alpha}^{0}}\right) .
$$

The per capita GDP effect:

$$
\Delta A=\sum_{i=1}^{n} \sum_{j=1}^{n} M_{\alpha i j} \ln \left(\frac{A^{t}}{A^{0}}\right) .
$$

The population size effect:

$$
\Delta P=\sum_{i=1}^{n} \sum_{j=1}^{n} M_{\alpha i j} \ln \left(\frac{P^{t}}{P^{0}}\right)
$$


Accordingly, we obtain the indirect carbon emissions from residential consumption, along with their variations induced by changes in each factor.

\section{Data Consolidation}

This paper takes the Liaoning province as the object of empirical research. Time-series input-output tables of Liaoning province (for the year 2002 [48], 2007 [49] and 2012 [50]) and the "Consumption of Energy by Sector" in the Liaoning Statistical Yearbook [51] for the respective years have been compiled. However, the classification between energy consumption categories and input-output sectors based on these data sources are not internally consistent; even the sectors of the IO tables in different years are different. In order to ensure comparability and consistency, the analysis presented in this paper integrates and unifies the energy consumption categories and input-output sectors into 29 new aggregation sectors, as shown in Table 1. The 29th factor in Table 1 "Other service sectors" includes finance and insurance, real estate, and other service-related activities.

Table 1. New sectors after aggregated.

\begin{tabular}{cccccc}
\hline No. & Sectors & No. & Sectors & No. & Sectors \\
\hline S1 & Agriculture & S11 & Petroleum & S21 & Other manufacturing \\
S2 & Mining of coal & S12 & Chemical industry & S22 & Scrap waste \\
S3 & Mining of oil and gas & S13 & Nonmetallic products & S23 & Electricity \\
S4 & Mining of metal & S14 & Metal smelting & S24 & Gas production \\
S5 & Mining of nonmetal & S15 & Fabricated metal products & S25 & Water production \\
S6 & Food and tobacco & S16 & Machinery manufacturing & S26 & Construction \\
S7 & Textile & S17 & Transport Equipment Manufacturing & S27 & Transport \\
S8 & Dressing & S18 & Electrical equipment manufacturing & S28 & Wholesale \\
S9 & Wood & S19 & Electronic equipment manufacturing & S29 & Other service sectors \\
S10 & Paper & S20 & Office machinery manufacturing & & \\
\hline
\end{tabular}

According to the integrated sector classification, input-output tables are fitted. Intermediate input, final demand and total output are obtained. Final demand is consolidated into two items: Rural residential consumption and urban residential consumption.

In order to eliminate the influence of price fluctuations, IO tables listing the present price for the 29 sectors are converted into equivalent year 2002 constant prices, using statistics from the Gross Domestic Product Index.

$$
C P=\frac{P P}{P I}
$$

where $C P$ is the constant price data; $P P$ is the present price data; and $P I$ is the price index. However, because of certain limitations of the price index as presently compiled in China, a unified price index has been adopted to the product sector. For instance, price adjustments for the agricultural sector use the producer price index for agricultural products. For manufacturing, ex-factory price indices for industrial products are used. For the construction industry, the construction and installation engineering price index are applied. The wholesale and retail sectors use the retail price index. Hotels and catering services use the dining out food price index. For finance and insurance, the financial price deflator is used. Real estate uses the real estate price index, and other sectors use the price index for services. Finally, intermediate input-output data and the aggregated output data of each sector are used to calculate the direct consumption coefficients per sector.

The data used in our model calculations are estimated using different reference sources for 9 types of fossil fuel consumption in each sector, including coal, coke, crude oil, gasoline, kerosene, diesel, fuel oil, natural gas and electricity. These alternative data are extracted from the Liaoning Statistical Yearbook [51] and China Energy Statistical Yearbook [52]. Carbon emission factors for energy (except electricity) are estimated based on the reference approach of the Intergovernmental Panel on Climate Change. Owing to the varied mix of energy inputs of power generation, the carbon emission factors for electricity are different from year to year. Another main aspect of data preparation for our study is 
estimating the carbon emission factors for electricity. The method used is to sum the carbon emission factors for all types of primary energy inputs, weighted by their quantity proportional to the amounts of total energy for power generation.

\section{Results and Discussion}

\subsection{Direct Carbon Emissions from Residential Consumption}

According to Equation (1), the direct carbon emissions of rural and urban residential consumption in Liaoning province can be calculated. As shown in Figure 1, the direct carbon emissions caused by rural and urban residents all show an increasing trend. Direct carbon emissions coming from rural residents increased from 0.99 million tons in 2002, to 2.22 million tons in 2012, a growth rate of $125 \%$. Direct carbon emissions coming from urban residents are significantly higher than those from rural. The emissions increased from 4.01 million tons in 2002, to 9.66 million tons in 2012, a growth rate of $141 \%$. Total direct carbon emissions increased from 5 million tons in 2002, to 11.87 million tons in 2012, or a growth rate of $137.4 \%$. As can be seen, the growth of direct carbon emissions coming from urban residents is the main source of the growth of total direct carbon emissions and the proportional increase from year to year. These urban direct emissions (as well as total emissions) will increase steadily in the future in Liaoning province. It is noteworthy that the relative growth rate of total direct emissions is on the decline, falling from 78.68\% between 2002 and 2007, down to $32.91 \%$ between 2007 and 2012 .

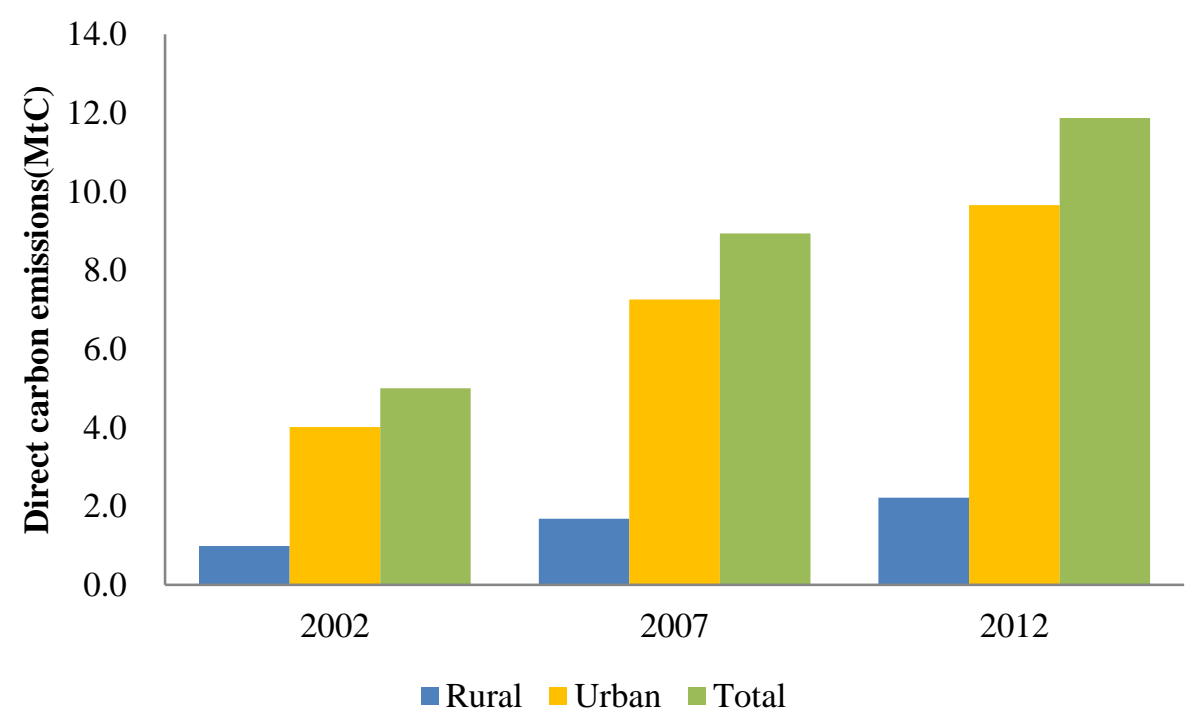

Figure 1. Direct carbon emissions of residential consumption in Liaoning province.

When analyzing the main causes of the above phenomenon, on the one hand, the direct consumption of total energy continues to grow. Urban residential direct energy consumption increased from 5.838 Mtce in 2002, to 13.934 Mtce in 2012. The direct energy consumption of rural residents increased from 1.435 Mtce to 3.196 Mtce during the same period, while total direct energy consumption increased from 7.272 Mtce to 17.13 Mtce. The growth rates were $138.68 \%, 122.72 \%$ and $135.56 \%$, respectively. This is basically consistent with the growth trend of carbon emissions. On the other hand, the change in the user structure of energy consumption is basically consistent with the change in the structure of emissions. In addition, due to historical factors and resources endowment, Liaoning province used coal and electricity as the main energy sources for a long time. In 2002, the consumption of coal accounted for $52.53 \%$ of total direct energy consumption; electricity was next, at $47.47 \%$. These energy consumption levels are relatively uniform. With the area's economic development, civilization advancement and improved living standards, different varieties of energy are becoming increasingly abundant. In 2012, the energy utilization structure of residents is changing, from the dual mode of just using coal and electricity, to choices now that include gasoline, diesel, natural gas and 
other options. The situation whereby coal and electricity account for a large proportion of energy use remains unchanged. It is noteworthy that Liaoning's electricity mostly comes from thermal power plants, whose technical level is relatively backward. This is one important reason why total emissions remain high.

\subsection{Indirect Carbon Emissions from Residential Consumption}

The indirect carbon emissions from rural and urban residential consumption can be calculated according to Equation (2). Indirect carbon emissions from rural and urban residential consumption continue to present an increasing trend, as shown in Figure 2. The growth of indirect carbon emissions from rural residents has been relatively slow, increasing from 17.4 million tons in 2002, to 27.5 million tons in 2012, or a growth rate of $58 \%$. The growth of indirect carbon emissions from urban residents has grown more rapidly, increasing from 60.1 million tons in 2002, to 142.8 million tons in 2012, or a growth rate of $137.6 \%$. Total indirect carbon emissions increased from 77.5 million tons to 170.3 million tons from 2002 to 2012, representing a growth rate of $119.7 \%$. It is obvious that urban residential consumption is the main reason behind the large growth of residential consumption-related indirect carbon emissions in Liaoning province.

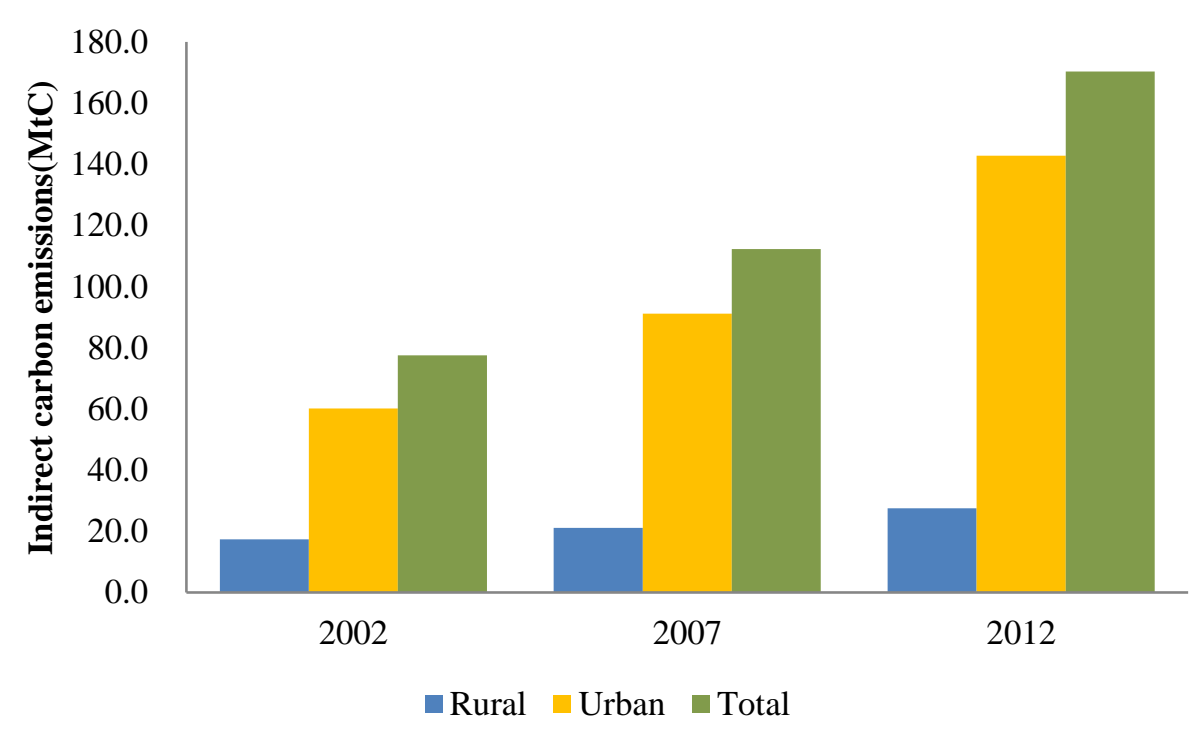

Figure 2. Indirect carbon emissions from residential consumption in Liaoning province.

The indirect carbon emissions caused by residents in Liaoning province (from the perspective of various sectors) can be seen in Table 2. From the perspective of indirect carbon emission amounts, for instance, in 2012, the sector with the most indirect emissions from residents is coal mining, which reached $6178.99 \times 10^{4} \mathrm{t}$. The next highest sector was electricity $\left(4861.76 \times 10^{4} \mathrm{t}\right)$ and then the oil and gas mining sector $\left(1272.69 \times 10^{4} \mathrm{t}\right)$. These three sectors accounted for $36.28 \%, 28.54 \%$ and $7.47 \%$ of total indirect emissions, respectively. With the development of China's economy and the corresponding growth in material needs, most of the sectoral indirect carbon emissions coming from residents showed an increasing trend. The greatest growth rate of indirect emissions is seen in the nonmetal mining sector, which increased from $12.84 \times 10^{4} \mathrm{t}$ in 2002 , to $190.31 \times 10^{4} \mathrm{t}$ in 2012 , representing an incredible grow rate of $1382.16 \%$. The sector with the second highest growth rate is construction, which increased by $1116.34 \%$, although the amount of actual emissions from this sector is relatively small. The food and tobacco as well as paper sectors showed a decreasing trend, with the indirect carbon emissions from these sectors decreasing by $26.06 \%$ and $12.17 \%$, respectively.

From the above-mentioned changes in emission structures, it can be seen that the coal mining and electricity sectors always generate the largest proportion of emissions. In addition, the sectors accounting for the larger proportions of indirect emissions changed from petroleum $(9.93 \%)$, chemical 
industry (3.92\%), mining of oil and gas (3.76\%), and paper $(3.75 \%)$ in 2002 , to mining of oil and gas $(7.47 \%)$, petroleum $(6.3 \%)$, the chemical industry $(3.36 \%)$ and metal smelting $(2.82 \%)$ in 2012 . The sectors with the biggest growth rate in terms of the proportion of emissions are the mining of nonmetal (574.61\%), construction (453.62), other manufacturing (355.69\%) and dressing $(174.14 \%)$. Accordingly, the sectors with the greatest reduction in the proportion of emissions produced are food and tobacco $(-66.35 \%)$, paper $(-60.02 \%)$, mining of metal $(-40.36 \%)$ and electrical equipment manufacturing $(-38.02 \%)$. Other sectors' changes in proportion were relatively small.

Table 2. Indirect carbon emissions from residents in Liaoning province, viewed from different sectors $\left(10^{4} \mathrm{tC}\right)$.

\begin{tabular}{|c|c|c|c|c|c|c|}
\hline & \multicolumn{2}{|c|}{2002} & \multicolumn{2}{|c|}{2007} & \multicolumn{2}{|c|}{2012} \\
\hline & Rural & Urban & Rural & Urban & Rural & Urban \\
\hline 1 & 20.03 & 38.46 & 24.28 & 73.10 & 33.45 & 136.27 \\
\hline 2 & 670.13 & 2209.36 & 708.92 & 3055.08 & 1017.57 & 5161.42 \\
\hline 3 & 64.72 & 226.43 & 83.56 & 378.06 & 197.48 & 1075.21 \\
\hline 4 & 12.16 & 41.35 & 23.79 & 98.97 & 11.69 & 58.43 \\
\hline 5 & 3.10 & 9.74 & 205.76 & 859.54 & 31.10 & 159.21 \\
\hline 6 & 22.05 & 66.73 & 19.82 & 72.84 & 13.63 & 52.01 \\
\hline 7 & 10.51 & 50.56 & 20.87 & 91.83 & 24.46 & 130.45 \\
\hline 8 & 1.22 & 5.68 & 4.39 & 22.09 & 6.16 & 35.38 \\
\hline 9 & 2.49 & 9.56 & 5.52 & 24.36 & 2.88 & 15.39 \\
\hline 10 & 56.55 & 234.51 & 116.74 & 517.68 & 41.41 & 214.23 \\
\hline 11 & 168.75 & 600.79 & 85.32 & 392.15 & 164.52 & 908.03 \\
\hline 12 & 79.31 & 224.36 & 91.12 & 366.40 & 96.28 & 475.81 \\
\hline 13 & 11.91 & 34.03 & 22.76 & 101.97 & 14.14 & 75.13 \\
\hline 14 & 37.32 & 129.26 & 53.27 & 221.51 & 80.08 & 400.15 \\
\hline 15 & 2.63 & 8.28 & 5.85 & 24.84 & 6.04 & 30.69 \\
\hline 16 & 1.97 & 6.49 & 3.60 & 14.91 & 3.91 & 19.49 \\
\hline 17 & 2.40 & 7.46 & 2.93 & 10.12 & 3.40 & 15.70 \\
\hline 18 & 2.91 & 11.78 & 3.04 & 12.28 & 3.43 & 16.58 \\
\hline 19 & 1.01 & 4.23 & 1.46 & 7.08 & 4.62 & 25.55 \\
\hline 20 & 1.83 & 6.88 & 4.82 & 21.81 & 8.74 & 44.98 \\
\hline 21 & 3.92 & 13.70 & 10.60 & 49.13 & 28.05 & 148.30 \\
\hline 22 & 0.00 & 0.00 & 0.00 & 0.00 & 0.00 & 0.00 \\
\hline 23 & 480.97 & 1729.57 & 311.69 & 1405.89 & 770.61 & 4091.15 \\
\hline 24 & 24.78 & 126.66 & 163.27 & 693.28 & 71.85 & 381.39 \\
\hline 25 & 12.17 & 47.35 & 55.15 & 239.70 & 17.70 & 89.17 \\
\hline 26 & 0.04 & 0.18 & 0.75 & 3.49 & 0.42 & 2.27 \\
\hline 27 & 36.81 & 135.57 & 69.88 & 301.06 & 73.86 & 388.38 \\
\hline 28 & 2.37 & 10.95 & 3.96 & 16.33 & 8.55 & 40.88 \\
\hline 29 & 5.29 & 23.16 & 8.95 & 41.35 & 16.47 & 88.47 \\
\hline Sub-Total & 1739.35 & 6013.06 & 2112.07 & 9116.85 & 2752.51 & $14,280.11$ \\
\hline Total & \multicolumn{2}{|c|}{7752.41} & \multicolumn{2}{|c|}{$11,228.93$} & \multicolumn{2}{|c|}{$17,032.62$} \\
\hline
\end{tabular}

\subsection{Total Carbon Emissions from Residential Consumption}

The total carbon emissions caused by residential consumption can be seen in Figure 3. As shown, total emissions increased from $82.52 \mathrm{MtC}$ in 2002 , to $182.2 \mathrm{MtC}$ in 2012. Of the main study categories, emissions caused by rural residential consumption increased from $18.4 \mathrm{MtC}$ to $29.7 \mathrm{MtC}$, and those caused by urban residential consumption increased from $64.1 \mathrm{MtC}$ to $152.5 \mathrm{MtC}$. The proportion of emissions from urban residential consumption accounted for $77.73 \%, 81.19 \%$ and $83.68 \%$, respectively, in 2002, 2007 and 2012. Considering the analysis of indirect emissions, it can be found that the growth in emissions caused by urban residential consumption (especially the indirect emissions caused by urban residents) is the main reason that the total carbon emissions caused by residents rapidly increased in Liaoning province. Interestingly, carbon emissions caused by rural residential consumption showed a 
downward trend in Geng et al.'s [41] research during the period of 1997-2007. This may be the reason for the time interval.

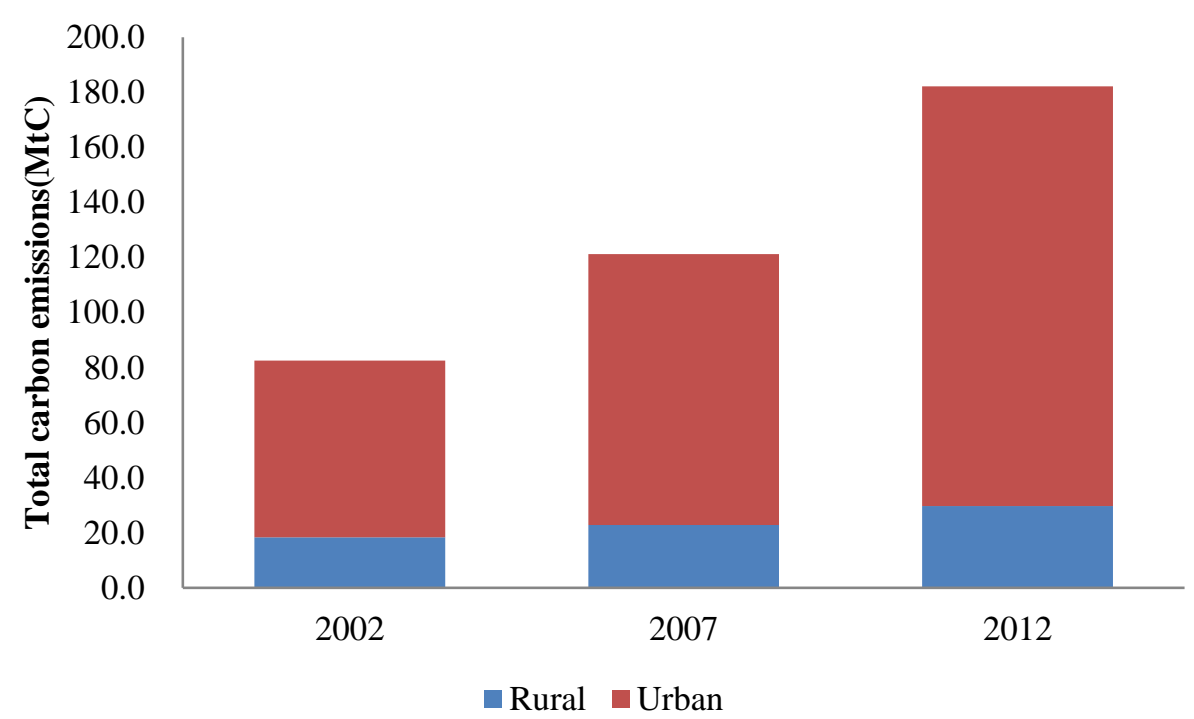

Figure 3. Total emissions from residential consumption in Liaoning province.

\subsection{Decomposed Results}

Based on the SDA and LMDI methods, the decomposition of indirect carbon emissions from residential consumption in rural and urban residents in Liaoning province was calculated. The results are displayed in Table 3, for the study period from 2002 to 2012, and for the eight prominent influencing factors.

Between 2002 and 2012, the overall increase of indirect carbon emissions caused by residential consumption in Liaoning province was $9280.21 \times 10^{4} \mathrm{t}$. The change in per capita GDP $(\Delta A)$ was the foremost factor in this increase, with $14,921.84 \times 10^{4} \mathrm{t}$, which actually exceeds the total net increase by $32.8 \%$. Under the effect of intermediate demand $(\Delta L)$, indirect carbon emissions caused by residential consumption increased to $11,839.25 \times 10^{4} \mathrm{t}$, which also played an important role. The increment of indirect carbon emissions caused by population $(\Delta P)$ and residential consumption structure $(\Delta U)$ is relatively small. Meanwhile, the change in energy intensity $(\Delta E)$ was the dominant factor behind indirect carbon emission reductions of $8144.35 \times 10^{4} \mathrm{t}$. The other two important factors were the commodity structure effect $(\Delta S)$ and the residential consumption ratio effect $(\Delta R)$, which contributed to indirect carbon emission reductions of $6473.34 \times 10^{4} \mathrm{t}$ and $3419.38 \times 10^{4} \mathrm{t}$, respectively. The change in carbon emission coefficient $(\Delta F)$ had a relatively small negative effect. It is worth noting that the change in residential consumption structure effect $(\Delta U)$ had a negative effect on the indirect carbon emissions caused by rural residents, but a positive effect on those caused by urban residents.

It is worth mentioning that the influence trend of most influencing factors in Liaoning was similar to results for Beijing [8]. The biggest difference is the carbon emission coefficient effect $(\Delta F)$. It reduced Liaoning's indirect carbon emissions caused by residents' consumption but increased in Beijing.

Indirect carbon emissions rose in most sectors, except for food and tobacco as well as paper, which experienced declines of $23.13 \times 10^{4} \mathrm{t}$ and $35.42 \times 10^{4} \mathrm{t}$, respectively. These declines were mostly caused by the effect of changes in energy intensity $(\Delta E)$. The sector that had the biggest increment was coal mining, with $3299.5 \times 10^{4} \mathrm{t}$, which was mostly caused by the effect of changes in intermediate demand $(\Delta L)$. 
Table 3. The results of decomposition of indirect carbon emissions caused by residential consumption in Liaoning province from 2002 to 2012 (unit: $10^{4} \mathrm{t}$ ).

\begin{tabular}{|c|c|c|c|c|c|c|c|c|c|c|c|c|c|c|c|c|c|}
\hline \multirow{2}{*}{ Sectors } & \multicolumn{2}{|c|}{$\Delta F$} & \multicolumn{2}{|c|}{$\Delta E$} & \multicolumn{2}{|c|}{$\overline{\Delta L}$} & \multicolumn{2}{|c|}{$\Delta S$} & \multicolumn{2}{|c|}{$\Delta U$} & \multicolumn{2}{|c|}{$\overline{\Delta R}$} & \multicolumn{2}{|c|}{$\Delta A$} & \multicolumn{2}{|c|}{$\Delta P$} & \multirow{2}{*}{$\begin{array}{c}\text { Total } \\
\text { Effect }\end{array}$} \\
\hline & Rural & Urban & Rural & Urban & Rural & Urban & Rural & Urban & Rural & Urban & Rural & Urban & Rural & Urban & Rural & Urban & \\
\hline 1 & -0.99 & -2.93 & 6.24 & 18.43 & 27.23 & 50.86 & -36.90 & -54.97 & -9.13 & 6.75 & -7.68 & -22.69 & 33.52 & 99.02 & 1.13 & 3.35 & 111.23 \\
\hline 2 & -0.81 & 3.38 & -697.04 & -2915.46 & 1924.25 & 6400.61 & -1446.07 & -4418.61 & -290.08 & 303.63 & -244.11 & -1021.02 & 1065.27 & & 36.02 & 150.66 & 3299.50 \\
\hline 3 & -1.33 & -6.10 & -77.25 & -353.68 & 130.21 & 599.53 & 0.00 & 0.00 & -41.50 & 47.55 & -34.92 & -159.90 & 152.40 & & 5.15 & 23.59 & 981.54 \\
\hline 4 & -0.22 & -0.93 & -11.01 & -45.60 & 2.63 & 8.39 & 0.00 & 0.00 & -4.16 & 4.31 & -3.50 & -14.50 & 15.27 & 63.26 & 0.52 & 2.14 & 16.61 \\
\hline 5 & -0.66 & -2.92 & 12.40 & 54.63 & 7.97 & 37.97 & 0.00 & 0.00 & -4.24 & 4. & -3.56 & -15.70 & 15.56 & 68.51 & 0.53 & 2.32 & 177.47 \\
\hline 6 & -0.75 & -2.54 & -16.20 & -54.68 & -3.43 & -3.57 & 0.04 & -19.94 & -6.10 & 5.15 & -5.14 & -17.33 & 22.41 & 75.64 & 0.76 & 2.56 & -23.13 \\
\hline 7 & -0.17 & -0.89 & -18.03 & -92.04 & 10.75 & 190.16 & 10.15 & -111.56 & -5.76 & 7.36 & -4.85 & -24.74 & 21.15 & 107.94 & 0.71 & 3.65 & 93.84 \\
\hline 8 & -0.12 & -0.62 & 1.61 & & 3.04 & 13.26 & -1.67 & -9.65 & -1.06 & 1. & -0.89 & & 3.90 & & 0.13 & & 34.64 \\
\hline 9 & -0.17 & -0.78 & -0.94 & -4.30 & 2.14 & 1.34 & -2.46 & -4.12 & -0.94 & 1.07 & -0.79 & 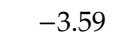 & 3.43 & & 0.12 & 0.53 & 6.22 \\
\hline 10 & -1.74 & -8.05 & -80.14 & -369.84 & 67.61 & 314.51 & -34.00 & -207.53 & -16.94 & 19.57 & -14.26 & -65.80 & 62.22 & 287.15 & 2.10 & 9.71 & -35.42 \\
\hline 11 & & & -118.35 & -52 & -33.40 & -470.80 & & 466.95 & -58.11 & 64.92 & -48.90 & -2 & 213.40 & & 7.22 & 32.21 & 303.01 \\
\hline 12 & -3.27 & -12 & -57.38 & -21 & 23.16 & 48.62 & -5.21 & 60 & -30.52 & 29. & -25.69 & & 112.09 & & 3.79 & 14.48 & 268.41 \\
\hline 13 & & & -3.48 & & 20.02 & 18. & -23.34 & -22 & -4.53 & 4. & -3.81 & & 16.64 & 66 & 0.56 & 2.25 & 43.32 \\
\hline 14 & 0.78 & & -32.01 & -137.02 & 35.81 & 136.62 & 0.00 & 0.00 & -19.53 & 20.92 & -16.44 & -70.35 & 71.72 & 307.01 & 2.43 & 10.38 & 313.66 \\
\hline 15 & -0.21 & -0.86 & -0.67 & -2.79 & 2.05 & -10.94 & -0.56 & 17.88 & -1.43 & 1.49 & -1.20 & -5.02 & 5.25 & 21.91 & 0.18 & 0.74 & 25.82 \\
\hline 16 & -0.11 & -0.45 & -0.09 & -0.38 & -1.00 & -6.57 & 1.21 & & -0.99 & & -0.83 & 2 & 3.63 & & 0.12 & 51 & 14.94 \\
\hline 17 & .20 & - & -2.55 & -9 & -0.65 & -11.01 & & & -1 & & -0.84 & -3 & 3 & & 0.12 & 0. & 9.23 \\
\hline 18 & -0.27 & -1 & -1.81 & -8 & -1.40 & 1. & & -3.61 & -1.10 & 1. & -0.93 & -4 & 4. & 17 & 0.14 & 0. & 5.32 \\
\hline 19 & -0.04 & -0.22 & 0.04 & 0.2 & 2.11 & 7. & -0.12 & 0.76 & -0.83 & 1. & -0.70 & -3 & 3.04 & 15 & 0.10 & 0.51 & 24.93 \\
\hline 20 & -0.44 & -2.02 & 2.09 & 9. & 11.49 & 38.45 & -9.24 & -30.58 & -1.54 & 1.7 & -1.30 & -5 & 5.66 & 25.98 & 0.19 & 0.88 & 45.02 \\
\hline 21 & -0.09 & -0.42 & -18.79 & -86.57 & -4.34 & 33.26 & 38.99 & 125.17 & -4.28 & 4.93 & -3.60 & -16.58 & 15.71 & 72.37 & 0.53 & 2.45 & 158.74 \\
\hline 22 & & & 0.00 & ת ח & م00 & & 0.00 & & 0.00 & 0. & 0.00 & 0.00 & 0.00 & 0.00 & 0.00 & 0.00 & 0.00 \\
\hline 23 & & & -298.72 & -1333.49 & 473.55 & 881.04 & -304.42 & -253.39 & -214.28 & 239.39 & -180.33 & -804.99 & 786.92 & 3512.89 & 26.61 & 118.78 & 2651.21 \\
\hline 24 & -1.21 & -6.3 & -73.17 & -382.37 & 160.24 & 472. & -68.94 & -87.11 & -15.42 & 20.17 & -12.98 & & 56.63 & 29 & 1.91 & 10.01 & 301.80 \\
\hline 25 & -1.36 & -6.07 & -10.94 & -48.97 & 22.80 & 86.66 & -15.03 & -63.64 & -5.15 & 5.77 & -4.33 & -19.39 & 18.91 & 84.61 & 0.64 & 2.86 & 47.36 \\
\hline 26 & -0.02 & -0.09 & -0.13 & -0.63 & 0.41 & 1.89 & 0.00 & 0.00 & -0.06 & 0.07 & -0.05 & -0.24 & 0.21 & 1.05 & 0.01 & 0.04 & 2.47 \\
\hline 27 & -0.58 & -2.61 & -21.56 & -97.36 & 38.45 & 131.95 & -15.53 & -47.68 & -18.55 & 20.96 & -15.61 & -70.49 & 68.13 & 307.62 & 2.30 & 10.40 & 289.85 \\
\hline 28 & -0.19 & -0.90 & 1.03 & 4.8 & -1.83 & 1.28 & 3.88 & -0.72 & -1.68 & 1.98 & -1.41 & -6.67 & 6.17 & 29.10 & 0.21 & 0.98 & 36.12 \\
\hline 29 & -0.65 & -3.22 & -3.23 & -16.01 & -0.28 & -0.17 & 8.64 & 30.25 & -3.43 & 4.25 & -2.89 & -14.30 & 12.60 & 62.40 & 0.43 & 2.11 & 76.50 \\
\hline Sub-Total & 12.59 & -53.51 & -1520.0 & -6624.28 & 2919.61 & 8973.64 & -1864.17 & -4609 & $7-762.33$ & 826.08 & -641.53 & -2777.85 & 2799.57 & $12,122.27$ & 94.66 & 409.88 & 9280.21 \\
\hline Forat & -0 & & & & 11,8 & 90.23 & -6473 & & & & -54 & & & & & & \\
\hline
\end{tabular}


The factors that had the most significant effect on the indirect carbon emissions caused by rural residential consumption was intermediate demand $(\Delta L)$, with per capita $\operatorname{GDP}(\Delta A)$ having the greatest effect on urban residential consumption. These two factors added $2919.61 \times 10^{4} \mathrm{t}$ and $12,122.27 \times 10^{4} \mathrm{t}$, respectively. From the perspective of a single department, under the influence of intermediate demand $(\Delta L)$, the consumption of the mining of coal by urban residents caused the most indirect carbon emissions, at $6400.64 \times 10^{4} \mathrm{t}$.

The following detailed discussion is offered in relation to the influencing factors, as shown in Table 3.

\subsubsection{The Carbon Emission Coefficient Effect}

The change in the carbon emission coefficient has an inhibitory effect on the carbon emissions of residents in Liaoning province. From 2002 to 2012, the indirect carbon emissions of rural and urban residents in Liaoning province decreased, with a contribution of $12.59 \times 10^{4} \mathrm{t}$ and $53.51 \times 10^{4} \mathrm{t}$, respectively. Since the carbon emission coefficients of the eight types of fossil energy are assumed to remain unchanged, the change in emission coefficients is actually the change in the emission coefficients of electric power. This shows that, on the one hand, the energy-saving technology of thermal power generation in Liaoning province has been improved. On the other hand, the proportion of primary energy generation (mainly hydropower and nuclear) in total power generation has increased. Then, combined with the situation in which the discharge coefficient of power gradually decreases, the promoting effect of coal share's increased electric power emission coefficient is absorbed by the improvement of energy-saving technology and the inhibiting effect brought about by the increase of primary energy utilization. This directly brings about the decline of the electric power emission coefficient, thus inhibiting the increase of the indirect carbon emissions of residents to some extent.

\subsubsection{The Energy Intensity Effect}

The energy intensity of the production sector shows a significant decline during the whole research period, which, when other conditions remain unchanged, greatly restrains the indirect emissions caused by residential consumption in Liaoning province. As can be seen in Table 3, the energy intensity of the production sector places the most important restraint on residential carbon emissions reduction in Liaoning province, and this is inseparable from China's long-term policy of adhering to the new path of industrialization. In the process of industrialization and urbanization, Liaoning province strives to pursue a production mode with high scientific and technological content, and with low environmental pollution and low resource consumption. Energy intensity has declined dramatically across the board, which is consistent with the research conclusion of Geng et al. [41].

Reducing energy intensity is the most important factor in urban residential carbon emissions reduction, which registered a contribution of $6624.28 \times 10^{4} \mathrm{t}$. Indirect carbon emissions, which were reduced by $1520.06 \times 10^{4} \mathrm{t}$, are affected by rural consumption energy intensity, which is the second-leading cause of rural emissions reduction (behind the consumption structure effect). Reducing the energy intensity of rural residents is an important research direction in efforts to reduce the energy intensity of residents' lives going forward. There is great untapped potential here.

With the rapid development of energy utilization technology, the improvement of energy intensity is being internationally recognized. This is especially true of energy output sectors, such as coal mining, and electricity and petroleum production. However, not all sectors are improving their energy intensity levels. Sectors such as nonmetal mining, dressing, electronic equipment manufacturing, office machinery manufacturing and wholesale have yet to make such improvements. With the restrictions of technology and scale, the costs of energy are called into question. The resulting energy consumption and carbon emissions are noteworthy.

From the perspective of the commodity energy consumption structure, the energy sources and consumption structure of coal and oil energy are fundamentally difficult to change in the short term. This is because the coal and oil energy infrastructure are so deeply entrenched. However, this matter 
will undoubtedly be addressed in the long term, given the mounting pressures being placed on the global coal industry with regard to climate change and air pollution. The adjustment of energy composition in Liaoning is imperative under the current situation, and definite progress has already been made, particularly with respect to new energy technology research and investment. To some extent, the progress already made will also improve energy efficiency and reduce energy intensity in the future.

\subsubsection{The Intermediate Demand Effects}

The intermediate demand of the production sector played the second largest positive role in increasing indirect carbon emissions in residential consumption. This means technological changes in the manufacturing sector create more carbon-intensive intermediate input demand. This is the leading cause of rural emissions incremental increases, with the contribution of $2919.61 \times 10^{4} \mathrm{t}$, and the second-leading cause of urban emissions incremental increases (behind per capita GDP), with a contribution of $8973.64 \times 10^{4} \mathrm{t}$. As can be seen from Table 3, most sectors contributed to the increase in indirect carbon emissions. The sectors responsible for the largest emissions growth were coal mining, oil and gas mining, and paper, electricity and gas production. As can be seen in the table, energy production is the main sector. The negative effect on indirect carbon emissions mainly comes from the petroleum sector. Other sectors have a relatively small promotional effect.

In order to truly reflect the influence of the intermediate demand effect from sector final production, a weighting method is introduced into this paper [8,53], as shown below:

$$
\delta_{j}=\frac{b_{d j}}{\sum_{j} b_{d j} \cdot \alpha_{j}}
$$

where $b_{i j}$ represents the element in the complete demand coefficients matrix of the input-output model. Then, $b_{d j}=\sum_{i} b_{i j} ; \alpha_{j}$ represents the proportion of the final production of sector $j$ in total final output, and $\delta_{j}$ is the influence coefficient, which represents the demand degree for sector $j$ in the intermediate production process. It is a dimensionless number and truly reflects the average pulling effect of the final product on the national economy: The greater its value, the greater influence of that sector on other sectors.

Figure 4 shows the influence coefficient of 29 selected sectors in 2002 and 2012. As can be seen, the influence coefficient for 15 sectors increased. The three sectors with the most significant increases were other manufacturing, electricity and petroleum, which rose by $145.55 \%, 65.89 \%$ and $47.24 \%$, respectively. In addition, the sectors with higher carbon emission intensity, such as coal mining, oil and gas mining, textiles, gas production and water production, rose by $13.33 \%, 7.27 \%, 26.63 \%, 46.01 \%$ and $21.15 \%$, respectively. There were also 14 sectors whose influence coefficients declined. The three sectors with the most significant declines were wholesale, metal mining and nonmetallic products, which decreased by $38.43 \%, 23.7 \%$ and $22.02 \%$, respectively. This article assumes that the 15 sectors with increasing influence coefficients and the 14 sectors with decreasing influence coefficients are taken as two separate entities. It is not difficult to find that the former is dominated by sectors with higher emission intensity, and the latter is dominated by sectors with lower emission intensity. The overall emission intensity of the former is higher than that of the latter. This means that, even if residents' consumption habits remain unchanged, indirect emissions from their consumption will increase as a result of this change in the input structure of the production sector. Special attributes of the "Old Industrial Base in Northeast China" also restrict the development of Liaoning Province. 


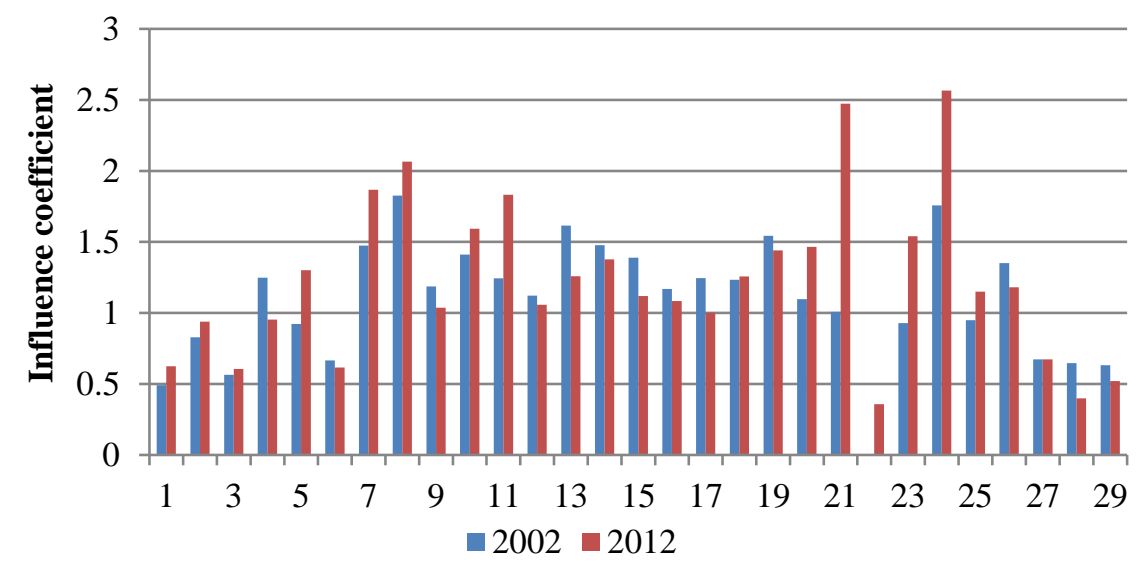

Figure 4. Influence coefficient of 29 sectors in 2002 and 2012 in Liaoning province.

\subsubsection{Commodity Structure Effect}

As shown in Table 3, the rural commodity structure had the biggest negative effect on the indirect carbon emissions caused by rural consumption, with a reduction of $1864.17 \times 10^{4} \mathrm{t}$. Indirect carbon emissions, which were reduced by $4609.17 \times 10^{4} \mathrm{t}$, were affected by the urban commodity structure, which was the second-leading cause of urban emission reduction (behind the energy intensity effect). From the perspective of the different sectors, whether rural or urban, the sectors responsible for the largest emission reduction were coal mining, and electricity and paper production, respectively. Conversely, the sectors with the biggest positive effect were petroleum, other manufacturing and other service sectors, respectively.

Figure 5 shows the commodity structure changes of rural and urban residents in Liaoning province during the study period. By analyzing the changes of commodity structure, the root cause of emission reduction can be discovered. Firstly, from the view of the changes between three industries in terms of residential consumption, it is obvious that the share of the primary industry fell sharply, from $31.63 \%$ in rural and $13.07 \%$ in urban in 2002 , down to $7.72 \%$ and $6.42 \%$ in 2012 , respectively. The share of the secondary industry fell from $43.53 \%$ in rural and $48.58 \%$ in urban in 2002 , down to $40.07 \%$ and $38.26 \%$ in 2012, respectively. The proportion of the tertiary industry increased markedly, rising from $24.85 \%$ in rural and $38.35 \%$ in urban in 2002 , to $52.21 \%$ and $55.33 \%$ in 2012 , respectively. To some extent, this reflects the residents' improvement in income and increased consumption levels, as well as the upgrading of Liaoning's industrial structure. The industrial structure of Liaoning province is gradually transferring to the tertiary industry, with low emission and high added value. Secondly, although the proportion of coal mining, and electricity and paper production of total residential consumption is relatively small, this proportion has still fallen dramatically. In addition, taking into account the three sectors, all of them belong to the sectors with high energy intensity. It is not difficult to explain the reduction effects of these three sectors. Thirdly, from the changes in the consumption expenditure structure, the consumption patterns of residents have increased the demand for carbon-intensive goods and services, such as petroleum, other manufacturing goods and other services. Such an incremental increase is offset by a decline in emissions, such as coal mining, which eventually curbs the carbon emissions caused by the change of the residential commodity structure. 

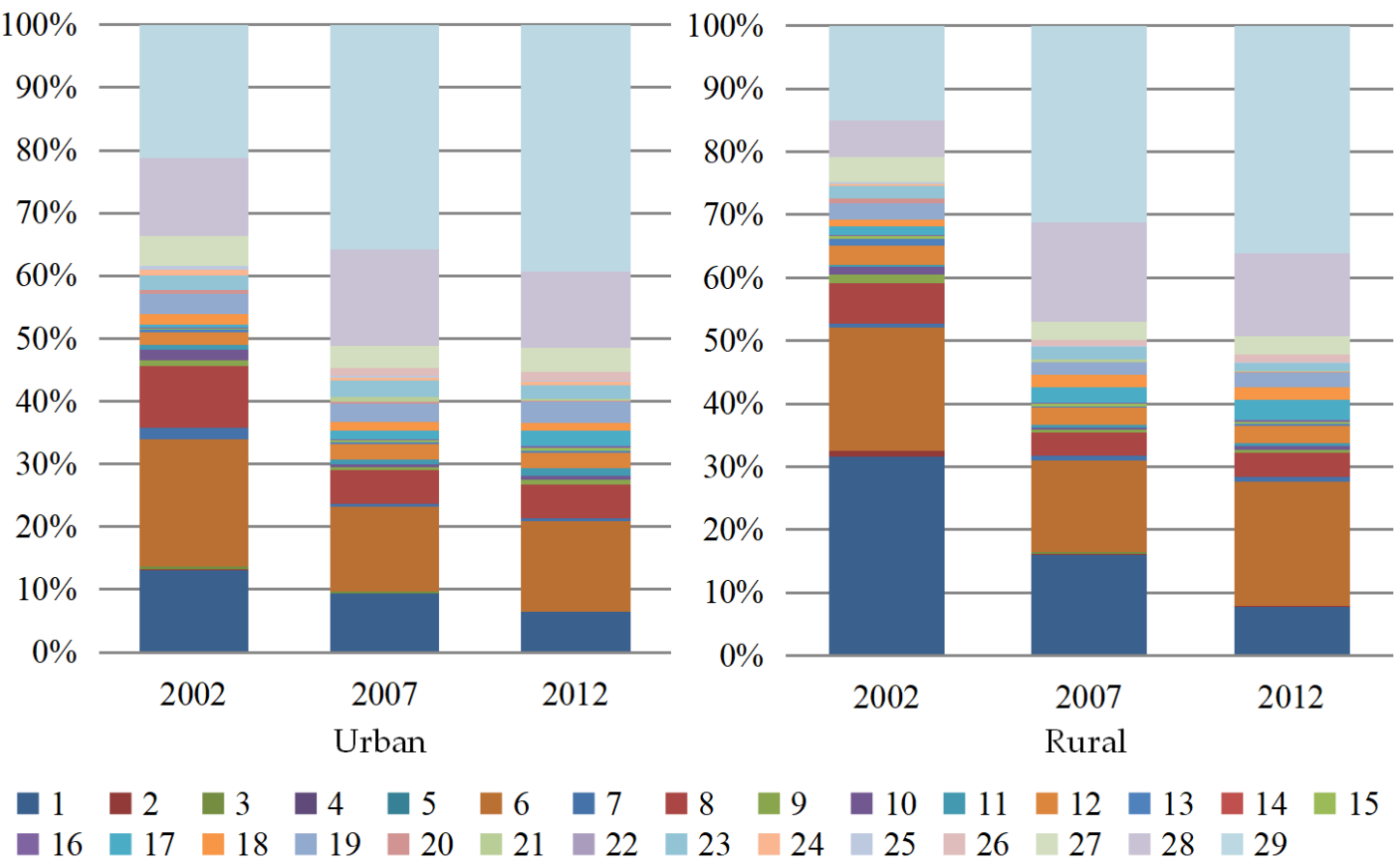

Figure 5. Commodity structure in urban and rural sectors in Liaoning province.

\subsubsection{The Residential Consumption Structure Effect}

During the ten-year study period, by changing the residential consumption structure, carbon emissions increased $63.74 \times 10^{4} \mathrm{t}$, which played a minimal incremental effect in emissions. Interestingly, when affected by the rural consumption structure changes, carbon emissions reduced by $762.33 \times 10^{4} \mathrm{t}$. On the contrary, carbon emissions increased by $826.08 \times 10^{4} \mathrm{t}$ under the effect of the urban consumption structure changes. Figure 6 shows the residential consumption structure in Liaoning province. The main reason for the changes to the consumption structure is the changes to the population structure. With the exacerbation of a socialist market economy, rural surplus population transferred into cities. Although the rural economy flourished and there were great changes in rural consumption, along with the corresponding rise in urbanization and an increase in residents' incomes, the demand from urban residents for material goods is much higher than the demand of rural residents. On this basis, the gap of emissions caused by the consumption structure will gradually widen.

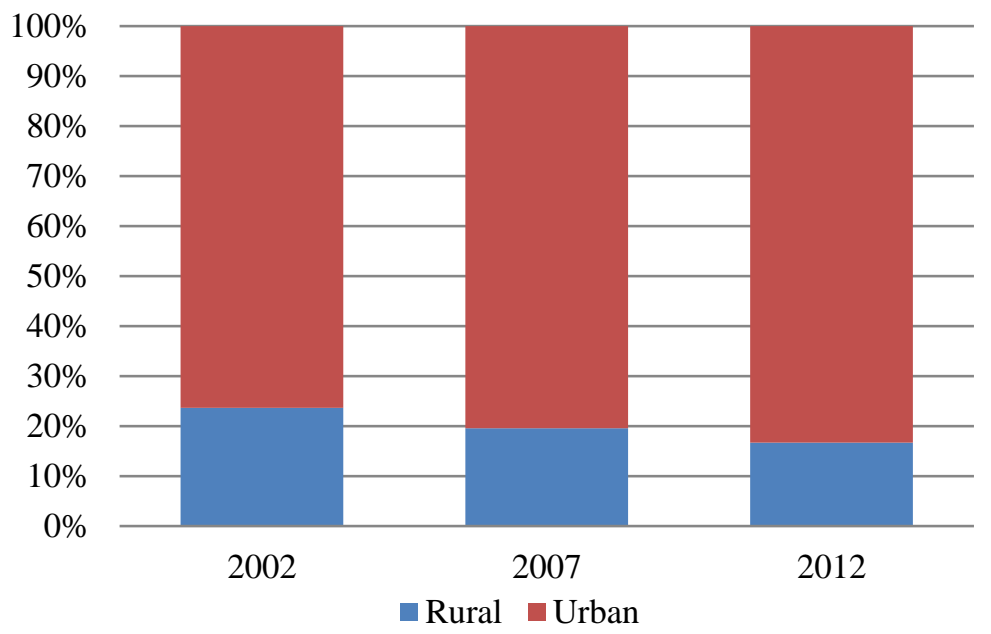

Figure 6. The residential consumption structure in Liaoning province. 


\subsubsection{The Residential Consumption Ratio Effect}

According to the input-output tables, final consumption includes household consumption, government consumption, gross domestic capital formation and net exports. Growth of the economy is measured by the gross domestic product (GDP), or the total output of goods and services in all sectors. Final consumption is an important component of GDP. Therefore, the residential consumption ratio is defined as the ratio of residential consumption to GDP. As shown in Table 3, the residential consumption ratio played an important role in reducing emissions, with a contribution of $3419.38 \times 10^{4} \mathrm{t}$. The impact of urban household consumption is even more pronounced. From 2002 to 2007, the residential consumption ratio declined from $13.89 \%$ in 2002 , to $10.35 \%$ in 2012 , which is the main reason the emissions decreased. It is worth noting that the ratio of final consumption to GDP increased from $36.87 \%$ in 2002 , to $56.49 \%$ in 2012 . This means that the ratio of other final consumption factors to GDP experienced substantial growth, and especially exports. Many researches have shown that exports are one of the key factors driving economic growth. However, exports are also an important factor behind the growth of carbon emissions. In other words, simply reducing the proportion of residential consumption cannot and will not actually reduce emissions. While ensuring steady economic growth, only a reasonable adjustment of the final consumption structure will achieve the effective control of total carbon emissions.

\subsubsection{The Per Capita GDP Effects}

As seen in Table 3, per capita GDP played the dominant role in adding indirect carbon emissions in both rural and urban Liaoning, from 2002 to 2012, with contribution values of $2199.57 \times 10^{4} \mathrm{t}$ and $12,122.27 \times 10^{4} \mathrm{t}$, respectively. Of all 26 sectors, the coal mining and electricity production sectors contributed the most. The final consumption of various goods and services actually reflects the change in residents' incomes. In the urbanization process, the income and final consumption of residents have both increased significantly. From 2002 to 2012, the per capita GDP of Liaoning residents increased from 58,731 yuan to 122,054 yuan, representing a growth rate of $107.8 \%$, as shown in Figure 7 . When both GDP and per capita GDP increase, residents' consumption awareness and consumption level will also increase, and the incremental increase of indirect carbon emissions caused by per capita GDP is unavoidable. The increase of household consumption is an inevitable phenomenon in the process of China's urbanization development. Therefore, it is unrealistic to expect or attempt to reduce consumption-related indirect carbon emissions by reducing consumption. However, what we can do is to guide the rational consumption mode, so that we will not increase or even reduce the carbon emissions of residents without reducing their welfare.

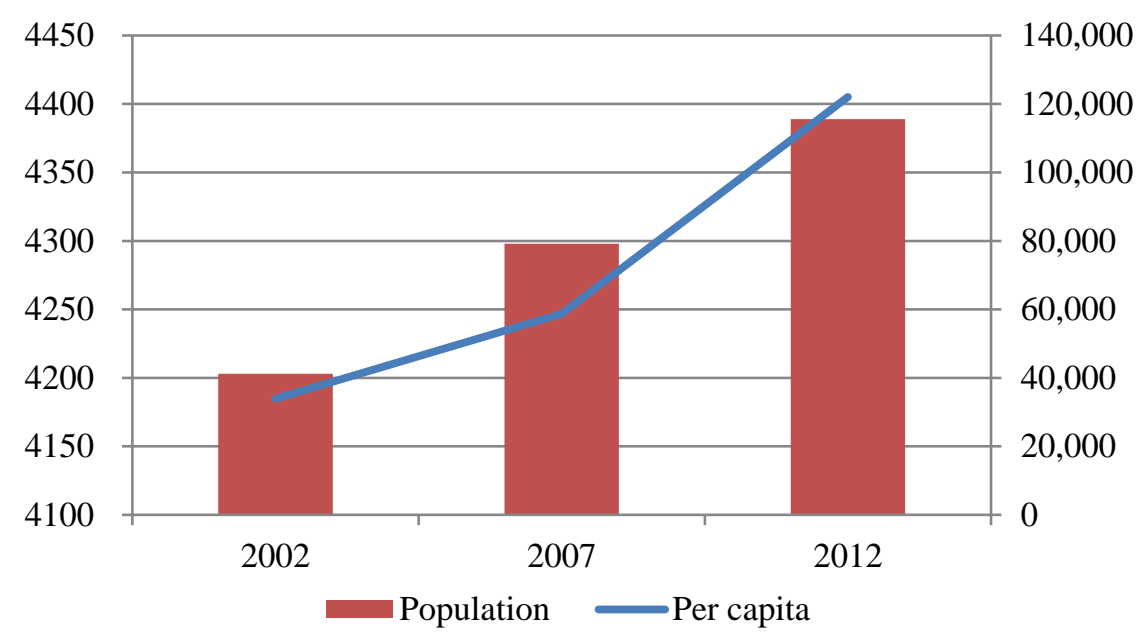

Figure 7. The per capita GDP and population in Liaoning province. 


\subsubsection{The Population Size Effects}

Amongst all of these effects, the population change in Liaoning province is regarded as playing a special role in driving demand. The population change effect is also a significant factor in analyzing changes in carbon emissions. As the nation's population was growing, so too were carbon emissions. With the population size effect, the indirect carbon emissions caused by urban and rural residents both increased. As seen in Table 3, out of all 26 sectors, coal mining contributed the largest amount of indirect carbon emissions, followed by electricity production. Liaoning is a large, populous province, with a variety of social classes and groups. The social makeup of the province determines its diversity and will not undergo any radical change quickly. Liaoning's population increased from 42.03 million in 2002, to 43.89 million in 2012, as shown in Figure 7. However, between 2002 and 2012, Liaoning's urbanization rate reached $65.64 \%$, considerably higher than the national average level $(52.57 \%)$. China's population policy has two objectives: Control population growth and improve population quality. Faced with a huge population base and an increasingly fast urbanization process, the demand for infrastructure and expendable supplies is growing rapidly. In addition, continuous upgrades to citizens' quality of life, consumption patterns and habits will change greatly. These changes are fully reflected in the high growth being experienced in the construction and services sectors, thus increasing carbon emissions.

\section{Discussions and Policy Implications}

By applying the IO-SDA and LMDI methods, drivers of Liaoning's indirect carbon emissions caused by residential consumption increase during 2002-2012 were uncovered. Indirect carbon emissions of residential consumption in Liaoning had increased by 92.8 million tons during the study period, with a growth rate of $119.7 \%$, indicating a fast growth of carbon emission in recent years. With the growth of per capita GDP, the increase of residents' total demand for final commodities was the main reason that indirect carbon emissions increased in Liaoning province. Besides, under the guidance of a policy entitled "rejuvenating the Old Northeastern Industrial Base of China", a great amount of investment was allocated to Liaoning province. However, the intermediate demand in Liaoning province was still dominated by sectors with higher emission intensity. Another key reason is that urbanization process was quickened and many rural populations moved to urban areas for jobs, resulting in a great demand on new residential apartments. Under such a rapid development, the shift in lifestyle exacerbated the final demand for high-carbon additional products. Meanwhile, energy structure in Liaoning province is dominated by fossil fuels, especially relying on coal and oil. Thus, the indirect carbon emissions from residential consumption in Liaoning had a dynamic increase.

This paper also makes an in-depth analysis of the influencing factors. The main recommendations are as follows: First of all, Liaoning should pay closer attention to the carbon emissions generated by residents' living sectors in the province's efforts to tackle and mitigate climate change. That means concrete mitigation measures should be prepared by considering the local realities. Secondly, through an analysis of the total carbon emissions assessment results of urban and rural residents in Liaoning province, it can be seen that a significant difference exists between the total carbon emissions of urban and rural residents. This provides a basis upon which Liaoning province can formulate relevant policies pertaining to low-carbon emission reduction and low-carbon transition for the benefit of its residents. Appropriate measures on changing the consumption pattern of urban residents need to be raised. Thirdly, we should guide urbanization toward maintaining a reasonable growth rate and moderate the scale of development. Urbanization nearly reflects the development and progress of an area, marking culture and civilization for one era. However, the construction of new rural areas should be actively promoted, and a healthy pattern of balanced development between urban and rural areas should be formed. Fourthly, we should improve the energy consumption structure and vigorously promote the use of clean energy. This has an important effect in increasing the efficiency of energy utilization and realizing sustainable energy development in Liaoning. Vigorous efforts should be made to develop low-carbon technologies, in order to improve the energy efficiency of production processes. Liaoning has made a plan to promote the development of natural gas, which will play a key role 
in the optimization of Liaoning's energy structure. In the urbanization process, green technological innovation should also be seen as a key opportunity to develop low-carbon economy and consumption. Fifthly, the state should formulate relevant policies that will help to adjust the population structure and improve the population quality of Liaoning province in the future. The population problem of Liaoning province not only has an important impact on the carbon emissions of residents' living sectors but is also a major problem facing all of China. Sixthly, guide residents towards living in a reasonable way. Guide people to carry on green consumption, cultivate awareness of environmental protection and optimization of living space. The consumption of residents has undergone tremendous changes, both in terms of quantity and structure, and the change of residents' lifestyles is the most important driving force behind the consumption of carbon emissions. Under the current circumstances of an extreme shortage of resources and energy in Liaoning province, the lifestyle of high-energy consumption and high emission is definitely not worth advocating. Seventhly, while the consumption level of residents is improving, they should not blindly increase their consumption expenditure on food. They should consume in a rational manner and refuse to waste. Governments at various levels should intensify propaganda work in order to raise social awareness of the significance of green consumption. Eighthly, strict energy consumption and emission standards should be formulated from the perspective of the energy industry, in order to achieve energy conservation and emission reduction in the consumer sector directly from the source. Tightly connect to the supply-side structural reform, promote the enterprises with high pollution to transform and upgrade. In short, on the premise of satisfying and maintaining a high quality of life, consumption in a more environmentally friendly form will be the main method for Liaoning residents to reduce carbon emissions in the future.

\section{Conclusions}

This paper calculated direct carbon emissions, based on the direct emission coefficient method, and also calculated indirect carbon emissions, based on an input-output model. A province with a higher urbanization rate (Liaoning) was selected as a case study area, and the research period was during 2002-2012. A comprehensive model of SDA and LMDI was further established, in order to analyze the factors that influence the indirect carbon emissions of Liaoning residents. The degree of the contribution of each factor was also analyzed. Based upon the analysis results, several mitigation policies have been raised by considering the local realities. Such a method can also be applied to analyze other Chinese regions so that more appropriate and effective carbon emission reduction policies can be prepared by considering their situations. The main conclusions are as follows:

The carbon emissions generated by the direct energy consumption of urban and rural residents show a rising trend year by year. Urban consumption is the primary generator of the two types. The reasons for these increases can be attributed to the increase in total energy and the relative lack of an energy structure.

The indirect carbon emissions caused by residential consumption also show a significant upward trend, and again, urban residents play an important role. The indirect carbon emissions caused by urban consumption are much higher than those caused by rural consumption. From a sectors' perspective, indirect carbon emissions in most sectors are growing. Coal has always been the biggest source of indirect carbon emissions, followed by electricity production. The sector with the greatest growth rate of indirect emissions is nonmetal mining. The food and tobacco, and paper sectors all show a decreasing trend.

The per capita GDP effect $(\Delta A)$ is the most important factor behind the increase in the indirect carbon emissions caused by household consumption in Liaoning. The GDP effect is followed by the intermediate demand effect $(\Delta L)$. The most important factor contributing to the reduction of indirect carbon emissions is energy intensity $(\Delta E)$, followed by the commodity structure effect $(\Delta S)$ and residential consumption ratio effect $(\Delta R)$. Other factors contribute relatively little to either the increase or decrease in emissions. The two factors that have the biggest influence on the indirect carbon 
emissions caused by rural and urban residential consumption are the intermediate demand effect $(\Delta L)$ and the per capita GDP effect $(\Delta A)$, respectively.

Among the factors that influence the indirect carbon emissions caused by rural residents, the commodity structure effect $(\Delta S)$ is the most important inhibiting factor, while per capita GDP $(\Delta A)$ is the most important promoting factor. Among the factors that influence the indirect carbon emissions caused by urban residents, the energy intensity effect $(\Delta E)$ is the most important inhibiting factor, while per capita GDP $(\Delta A)$ is the most important promoting factor.

It is worth mentioning that the residential consumption structure effect $(\Delta U)$ inhibits the indirect carbon emissions caused by the consumption of rural residents, but the same effect promotes the indirect carbon emissions caused by the consumption of urban residents.

At the same time, this paper also has some limitations. Firstly, the model in this paper has high application value in analyzing the impact of indirect carbon emissions. However, the limited data available makes further interpretation difficult, such as IO tables and energy data. Secondly, this paper decomposes the influence of indirect carbon emissions into eight objective factors. In fact, in conclusion the writers point out that green consumption occurs not only for objective factor reasons, but is also caused by psychological factors. Residents' income and education level also have an impact on indirect carbon emissions caused by the consumption of residents. All of these will be considered in the follow-up study.

Author Contributions: Conceptualization, Y.Y.; data curation, Y.Y. and S.G.; formal analysis, Y.Y.; funding acquisition, C.W.; investigation, Y.Y. and S.G.; methodology, Y.Y.; project administration, C.W.; supervision, A.P. and C.W.; visualization, S.G.; writing-original draft, Y.Y.; writing—review and editing, A.P.

Funding: The authors gratefully acknowledge the financial support from National Natural Science Foundation of China (Grant No. 71320107006) and National Social Science Foundation (Grant No. 14AZD090).

Acknowledgments: We would like to thank the anonymous referees for their helpful suggestions and corrections on the earlier draft of our paper, and upon which we have improved the content.

Conflicts of Interest: The authors declare no conflict of interest.

\section{References}

1. International Energy Agency (IEA). World Energy Outlook 2010; IEA: Paris, France, 2010.

2. Guan, D. The gigatonne gap in China's carbon dioxide inventories. Nat. Clim. Chang. 2012, 2, $672-675$. [CrossRef]

3. Fan, J.-L.; Yu, H.; Wei, Y.-M. Residential energy-related carbon emissions in urban and rural China during 1996-2012: From the perspective of five end-use activities. Energy Build. 2015, 96, 201-209. [CrossRef]

4. Fonseca, L.; Domingues, P.; Pereira, M.; Martins, F.; Zimon, D. Assessment of circular economy within Portuguese organizations. Sustainability 2018, 10, 2521. [CrossRef]

5. Shaharudin, M.S.; Fernando, Y.; Jabbour, C.J.C.; Sroufe, R.; Jasmi, M.F.A. Past, present, and future low carbon supply chain management: A content review using social network analysis. J. Clean. Prod. 2019, 218, 629-643. [CrossRef]

6. Zhu, Q.; Peng, X.; Wu, K. Calculation and decomposition of indirect carbon emissions from residential consumption in China based on the input-output model. Energy Policy 2012, 48, 618-626. [CrossRef]

7. Yuan, B.; Ren, S.; Chen, X. The effects of urbanization, consumption ratio and consumption structure on residential indirect $\mathrm{CO}_{2}$ emissions in China: A regional comparative analysis. Appl. Energy 2015, 140, 94-106. [CrossRef]

8. Wang, Z.; Yang, Y. Features and influencing factors of carbon emissions indicators in the perspective of residential consumption: Evidence from Beijing, China. Ecol. Indic. 2016, 61, 634-645. [CrossRef]

9. Jiang, J. China's urban residential carbon emission and energy efficiency policy. Energy 2016, 109, 866-875. [CrossRef]

10. Miao, L. Examining the impact factors of urban residential energy consumption and $\mathrm{CO}_{2}$ emissions in China-Evidence from city-level data. Ecol. Indic. 2017, 73, 29-37. [CrossRef] 
11. Wang, C.; Zhan, J.; Li, Z.; Zhang, F.; Zhang, Y. Structural decomposition analysis of carbon emissions from residential consumption in the Beijing-Tianjin-Hebei region, China. J. Clean. Prod. 2019, 208, 1357-1364. [CrossRef]

12. Wang, Z.H.; Yang, L. Indirect carbon emissions in household consumption: Evidence from the urban and rural area in China. J. Clean. Prod. 2014, 78, 94-103. [CrossRef]

13. Su, B.; Ang, B.W. Structural decomposition analysis applied to energy and emissions: Some methodological developments. Energy Econ. 2012, 34, 177-188. [CrossRef]

14. Lenzen, M. Primary energy and greenhouse gases embodied in Australian final consumption: An input-output analysis. Energy Policy 1998, 26, 495-506. [CrossRef]

15. Weber, C.; Perrels, A. Modelling lifestyle effects on energy demand and related emissions. Energy Policy 2000, 28, 549-566. [CrossRef]

16. Rhee, H.-C.; Chung, H.-S. Change in $\mathrm{CO}_{2}$ emissions and its transmission between Korea and Japan using international input-output analysis. Ecol. Econ. 2006, 58, 788-800. [CrossRef]

17. Liu, L.-C.; Wu, G.; Wang, J.-N.; Wei, Y.-M. China's carbon emissions from urban and rural households during 1992-2007. J. Clean. Prod. 2011, 19, 1754-1762. [CrossRef]

18. Fan, J.; Guo, X.; Marinova, D.; Wu, Y.; Zhao, D. Embedded carbon footprint of Chinese urban household: Structure and changes. J. Clean. Prod. 2012, 33, 50-59. [CrossRef]

19. Li, Y.; Zhao, R.; Liu, T.; Zhao, J. Does urbanization lead to more direct and indirect household carbon dioxide emissions? Evidence from China during 1996-2012. J. Clean. Prod. 2015, 102, 103-114. [CrossRef]

20. Ma, X.-W.; Du, J.; Zhang, M.-Y.; Ye, Y. Indirect carbon emissions from household consumption between China and the USA: Based on an input-output model. Nat. Hazards 2016, 84, 399-410. [CrossRef]

21. Peters, G.P.; Weber, C.L.; Guan, D. China's Growing $\mathrm{CO}_{2}$ Emissions A Race between Increasing Consumption and Efficiency Gains. Environ. Sci. Technol. 2007, 41, 5939-5944. [CrossRef]

22. Guan, D.; Hubacek, K.; Weber, C.L.; Peter, G.P.; Reiner, D.M. The drivers of Chinese $\mathrm{CO}_{2}$ emissions from 1980 to 2030. Glob. Environ. Chang. 2008, 18, 626-634. [CrossRef]

23. Tian, X.; Chang, M.; Tanikawa, H.; Shi, F.; Imura, H. Structural decomposition analysis of the carbonization process in Beijing: A regional explanation of rapid increasing carbon dioxide emissions in China. Energy Policy 2013, 53, 279-286. [CrossRef]

24. Gui, S.; Mu, H.; Li, N. Analysis of impact factors on China's $\mathrm{CO}_{2}$ emissions from the view of supply chain paths. Energy 2014, 74, 405-416. [CrossRef]

25. Wang, C.; Wang, F. Structural Decomposition Analysis of Carbon Emissions and Policy Recommendations for Energy Sustainability in Xinjiang. Sustainability 2015, 7, 7548-7567. [CrossRef]

26. Xu, S.-C.; Zhang, L.; Liu, Y.-T.; Zhang, W.-W.; He, Z.-X.; Long, R.-Y.; Chen, H. Determination of the factors that influence increments in $\mathrm{CO}_{2}$ emissions in Jiangsu, China using the SDA method. J. Clean. Prod. 2017, 142, 3061-3074. [CrossRef]

27. Xu, S.; Zhang, W.; Li, Q.; Zhao, B.; Wang, S.; Ruyin, L. Decomposition Analysis of the Factors that Influence Energy Related Air Pollutant Emission Changes in China Using the SDA Method. Sustainability 2017, 9, 1742. [CrossRef]

28. Yan, J.; Su, B.; Liu, Y. Multiplicative structural decomposition and attribution analysis of carbon emission intensity in China, 2002-2012. J. Clean. Prod. 2018, 198, 195-207. [CrossRef]

29. Dietzenbacher, E.; Los, B. Structural Decomposition Techniques: Sense and Sensitivity. Econ. Syst. Res. 1998, 10, 307-323. [CrossRef]

30. Dietzenbacher, E.; Los, B. Structural Decomposition Analyses with Dependent Determinants. Econ. Syst. Res. 2000, 12, 497-514. [CrossRef]

31. Ang, B.W.; Zhang, F.Q.; Choi, K. Factorizing Changes in Energy and Environmental Indicators through decomposition. Energy 1998, 23, 489-495. [CrossRef]

32. Wang, H.; Ang, B.W.; Su, B. Assessing drivers of economy-wide energy use and emissions: IDA versus SDA. Energy Policy 2017, 107, 582-599. [CrossRef]

33. Wang, P.; Wang, C.; Hu, Y.; Liu, Z. Analysis of energy consumption in Hunan Province (China) using a LMDI method based LEAP model. Energy Procedia 2017, 142, 3160-3169. [CrossRef]

34. Wang, M.; Feng, C. Decomposing the change in energy consumption in China's nonferrous metal industry: An empirical analysis based on the LMDI method. Renew. Sustain. Energy Rev. 2018, 82, 2652-2663. [CrossRef] 
35. Chai, J.; Liang, T.; Lai, K.K.; Zhang, Z.G.; Wang, S. The future natural gas consumption in China: Based on the LMDI-STIRPAT-PLSR framework and scenario analysis. Energy Policy 2018, 119, 215-225. [CrossRef]

36. Mousavi, B.; Lopez, N.S.A.; Manuel Biona, J.B. Driving forces of Iran's $\mathrm{CO}_{2}$ emissions from energy consumption: An LMDI decomposition approach. Appl. Energy 2017, 206, 804-814. [CrossRef]

37. De, O.J.; Paulo, M. Effect of generation capacity factors on carbon emission intensity of electricity of Latin America \& the Caribbean, a temporal IDA-LMDI analysis. Renew. Sustain. Energy Rev. 2019, 101, 516-526.

38. Ang, B.W. LMDI decomposition approach: A guide for implementation. Energy Policy 2015, 86, $233-238$. [CrossRef]

39. Wang, Z.H.; Liu, W.; Yin, J.H. Driving forces of indirect carbon emissions from household consumption in China: An input-output decomposition analysis. Nat. Hazards 2014, 75, 257-272. [CrossRef]

40. O'Neil, B.; Dalton, M.; Fuchs, R.; Jiang, L.; Pachauri, S.; Zigova, K. Global demographic trends and future carbon emissions. Proc. Natl. Acad. Sci. USA 2010, 107, 17521-17526.

41. Geng, Y.; Zhao, H.Y.; Liu, Z.; Xue, B.; Fujita, T.; Xi, F.M. Exploring driving factors of energy-related $\mathrm{CO}_{2}$ emissions in Chinese provinces: A case of Liaoning. Energy Policy 2013, 60, 820-826. [CrossRef]

42. Liu, L.; Qu, J.; Afton, C.-S.; Tek, N.M.; Pang, J. Spatial variations and determinants of per capita household $\mathrm{CO}_{2}$ emissions (PHCEs) in China. Sustainability 2017, 9, 1277. [CrossRef]

43. Wang, W.X.; Kuang, Y.Q.; Huang, N.S. Study on the decomposition of factors affecting energy-related carbon emissions in Guangdong province, China. Energies 2011, 4, 2249-2272. [CrossRef]

44. Qu, J.; Tek, M.; Liu, L.; Zhang, Z.; Talal, Y. A comparison of household carbon emission patterns of urban and rural China over the 17 years period (1995-2011). Energies 2015, 8, 10537-10557. [CrossRef]

45. Xu, X.; Huo, H.; Liu, J.; Shan, Y.; Li, Y.; Zheng, H.; Guan, D.; Ouyang, Z. Patterns of $\mathrm{CO}_{2}$ emissions in 18 central Chinese cities from 2000 to 2014. J. Clean. Prod. 2017, 172, 529-540. [CrossRef]

46. IPCC. Climate Change 2007: The Physical Science Basis. Contribution of Working Group I to the Fourth Assessment Report of the Intergovernmental Panel on Climate Change; Cambridge University Press: Cambridge, UK; New York, NY, USA, 2007.

47. Wachsmann, U.; Wood, R.; Lenzen, M.; Schaeffer, R. Structural decomposition of energy use in Brazil from 1970 to 1996. Appl. Energy 2009, 86, 578-587. [CrossRef]

48. National Bureau of Statistics of China (NBSC). China Regional Input-Output Table, 2002; China Statistics Press: Beijing, China, 2008.

49. National Bureau of Statistics of China (NBSC). China Regional Input-Output Table, 2007; China Statistics Press: Beijing, China, 2011.

50. National Bureau of Statistics of China (NBSC). China Regional Input-Output Table, 2012; China Statistics Press: Beijing, China, 2018.

51. Statistics Bureau of Liaoning Province (SBLP). Liaoning Statistical Yearbook, 2003-2013; China Statistics Press: Beijing, China, 2004-2014.

52. National Bureau of Statistics of China (NBSC). China Energy Statistical Yearbook, 2003-2013; China Statistics Press: Beijing, China, 2004-2014.

53. Liu, Q. Research on analysis method of input-output coefficient structure. Stat. Res. 2002, 2, 40-42.

(C) 2019 by the authors. Licensee MDPI, Basel, Switzerland. This article is an open access article distributed under the terms and conditions of the Creative Commons Attribution (CC BY) license (http://creativecommons.org/licenses/by/4.0/). 